\title{
Aristotle on Responsibility for One's Character and the Possibility of Character Cbange ${ }^{1}$
}

\author{
WILLIAM BONDESON
}

A ristotle's discussion of the voluntary and the involuntary occurs in Book III, chapters 1 through 5, of the Nicomachean Ethics. $\mathrm{He}$ is concerned to assess the conditions under which a) an action and b) a state of character can be called voluntary or involuntary. And he wants to make the important point that only voluntary. actions and voluntarily acquired states of character are praiseworthy or blameworthy and that men can be held responsible only for these kinds of actions and states of character. In this discussion I am only concerned with Aristotle's views concerning one of the conditions under which men can be held responsible for their states of character although this has implications for his analysis of the nature of human action and the relation of knowledge to the virtues.

If, under some conditions at least, men can be held responsible for their states of character, some related questions arise. Is it possible to act contrary to an established state of character? Is it possible to form contrary states of character by performing actions contrary to an established state of character? Is, for example, the habitual coward doomed to live out his state of character or is moral reform possible?

In the opening lines of Book II, Aristotle implies that character change is possible. Moral virtue arises in men, unlike intellectual virtue, by habituation and thus

"it is also plain that none of the moral virtues arise in us by nature; for nothing that exists by nature can form a habit contrary to its nature." (1103 a 19-20, Ross trans.)

He goes on to point out that stones cannot be habituated to fall upwards nor can fire be habituated to move downwards. He is implying that those states of character which are the moral virtues are not naturally acquired and by the (assumed) principle that things in men which do not exist or arise by nature are changeable, he maintains that men indeed can act contrary to their states of character. By

1 This paper has had the benefit of suggestions from David Furley, Warner Wick and William Wilcox for which they are to be thanked. 
implication, it should be possible for men to build new states of character. In the Categories Aristotle clearly states that character change can occur:

"The bad man, if he is being brought into a better way of life and thought, may make some advance, however slight, and if he should once improve, even ever so little, it is plain that he might change completely, or at any rate make very great progress; for a man becomes more and more easily moved to virtue, however small the improvement was at first. It is, therefore, natural to suppose that he will make yet greater progress than he has made in the past; and as this process goes on, it will change him completely and establish in him a contrary state, provided he is not hindered by lack of time." (13 a 23 -13 a 31, Ross trans.) ${ }^{2}$

However, in Book III, chapter 5 of the Ethics, Aristotle makes a point which would seem to contradict this altogether. Aristotle says:

"We may suppose a case in which (a man) is ill voluntarily through living incontinently and disobeying his doctors. In that case it was then open to him not to be ill, but not now, when he has thrown away his chance, just as when you let a stone go, it is too late to recover it; but yet it was in your power to throw it, since the moving principle was in you. So, too, to the unjust and to the self-indulgent man it was open at the beginning not to become men of this kind, and so they are unjust and selfindulgent voluntarily; but now that they have become so it is not possible for them not to be so." (1114 a 15-22, Ross trans.)

In a very perceptive interpretation of Aristotle's views, ${ }^{3}$ F. A. Siegler has discussed this passage. Siegler argues that the stone analogy is misleading ${ }^{4}$ and he cites 1103 a 19-20 which I have pointed out above. By any interpretation of this earlier passage it would be unlikely

2 This passage, although it establishes the possibility of character change, is not as strong as one would like. How is the bad man "brought" into a better way of life? The use of the passive voice might indicate that a man is being reformed morally by someone other than himself but it does not rule out the possibility, important for the purposes of this paper, that a man might be his own moral reformer.

3 "Voluntary and Involuntary," Monist, vol, 52, no. 2 (April, 1968) pp. 268-287. - The references to this and a preceding passage in Siegler's article are incorrect. At the bottom of page 284 he is quoting 1114 a $4-1114$ a 8 and at the top of page 285 he is quoting 1114 a $13-1114$ a 22. 
that Aristotle would maintain that every state of character is like a stone once it is thrown although it is an open question as to what would count as a changeable state of character and also whether there are some states of character (how are these to be identified?) for which change is impossible. The passage in which states of character are like thrown stones (1114 a 15-22) Siegler shows to be a special case and not contrary to Aristotle's view in the earlier passage. Siegler says,

"In this passage Aristotle is concerned only with acts done in ignorance due to carelessness (vide the preceding passage 1114 a 1 1114 a 3.) Unlike a greedy man whose greedy acts-in characterare themselves voluntary, the careless man acts in ignorance and therefore involuntarily. But, nevertheless, just as with other character traits, a careless man has become so voluntarily, knowing what kind of person he risks becoming... Thus the careless man who acts in ignorance of a particular does not act voluntarily, but he is to blame for the harm he causes since his act is the result of his bad character for which he is to blame."5 (my italicis)

I should like to argue that Siegler and, as far as I can discover, all of Aristotle's commentators have failed to notice an additional point which appears to be crucial to understanding Aristotle's account of both how men can be held responsible for their states of character and how character change is possible. That point is hinted at by Siegler in that portion of the quote above which $I$ have underlined, but the point is made very clearly by Aristotle:

"Now not to know that it is from the exercise of activities on particular objects that states of character are produced is the

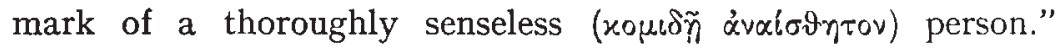
(1114 a 9 - 1114 a 11 Ross trans. $)^{6}$

Fundamental to the understanding of this passage is the meaning of

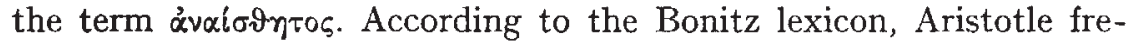
quently uses the term to mean a failure of or lack of some sensory organ. Clearly this cannot be the way he uses the term here. He also uses the term to mean the inability to feel pleasure, and this cannot

5 Ibid., p. 286.

- Rackham, in the Loeb Classical Library edition, translates this as: "Therefore only an utterly senseless person can fail to know that our characters are the result of our conduct." (p. 147) 
be the meaning of the term here either. ${ }^{7}$ Rather than these meanings, Bonitz cites this passage and three other passages in which the term means the opposite of supuris. ${ }^{8}$ And this meaning fits the context of the passage under discussion. Thus the term probably means not being a sensible person, not having good sense, or not having common sense. And the addition of $x o \mu r \delta \tilde{n}$ makes it plausible to render the phrase as Ross does.

This item of knowledge, Aristotle seems to be saying, is widely

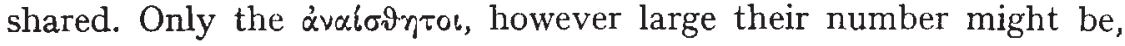
are unaware of this apparently basic truth. But in what ways are men aware of this and what is the status of this item of knowledge in Aristotle's moral psychology? The sentences immediately preceding the passage in question make it clear that the item of knowledge at least is exhibited in practice:

"... for it is activities exercised on particular objects that make the corresponding character. This is plain from the case of people training for any contest or action; they practise the activity the whole time." (1114 a 6-1114 a 9, Ross trans.)

Since Aristotle is here talking about training for athletic activities, he must want to say that a principle which applies to physical skills must have an analogue in the case of moral activities. ${ }^{9}$ But if the actions that men perform lead to the establishment of states of character (and conversely that states of character lead to the performance of corresponding kinds of actions) then, Aristotle is arguing, this knowledge plays an important role in establishing states of character and also in changing them. However, young children apparently

7 For the use of the term to mean the lack or failure of some sensory capacity, vide, e.g., Part. An. 667 a 13, Hist. An. 517 b 31, 635 b 10, 634 a 4, Physics 245 a 10. For the passive construction, vide Gen. et Corr. 332 a 35, Problems $964 \mathrm{~b} \mathrm{24,} \mathrm{Physics} 222 \mathrm{~b} 15$. For the use of the term to mean incapacity to feel pleasure, vide, e.g., Nic. Eth. 1104 b 24, 1107 b 8, Eud. Eth. 1221 a 21, 1230 b 14, and 1231 a 26.

8 Unfortunately these works are considered spurious: Physiognomica $806 \mathrm{~b} 22$, 807 b 19, Magna Moralia 1213 a 5. The Magna Moralia passage comes the closest to meaning the opposite of eúpuns.

'How far should Aristotle's analogy be followed here? In the case of athletic training the failure to keep to a training schedule can lead to the opposite of the conditioned state. And keeping in condition requires continued and regular training. That not practising a moral virtue will inevitably lead to its opposite vice is not obvious, nor is it obvious that practising the virtues must be done with the frequency and regularity of a training schedule. 
do not have this knowledge, yet they can have and acquire states of character. Thus it is not likely that Aristotle is saying that having this knowledge is a necessary condition for establishing a state of character. One might not need to know that performing a particular action will produce a corresponding state of character in order for that action to produce that state of character. Aristotle might be saying, although the text is not at all clear on this, that having this knowledge is what makes states of character morally appraisable.

Several questions can be raised about this item of knowledge:

1) How is it known?

2) Who knows it and how is the man ignorant of this knowledge to be characterized?

3) How is this item of knowledge related to the claim that men, at least in some cases, can be held responsible for their states of character?

4) How is this item of knowledge related to the claim that, at least in some cases, character change or moral reform is possible?

5) Could a man ignorant of this item of knowledge be held responsible for his states of character and could he change his character?

Question 1) can be answered rather clearly from Aristotle's text. At the minimum the example of athletic training shows that some men make use of the item of knowledge in one area of human activity. But, in the main passage under discussion here Aristotle claims that only the stated in its most general form. Thus Aristotle seems to want to claim that not only is the item of knowledge exhibited in practice but also

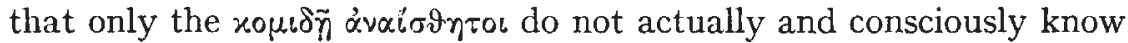
it. But how is this known? I cannot find any direct answer to this question in the text but I would suggest that this item could well fall within the class of $\varepsilon v \delta \circ \xi \alpha$, those widely held views of men about moral and other matters, which Aristotle often uses in his philosophizing. ${ }^{10}$ The first chapter of the first book of the Ethics contains many of these, for example the views about the final end of human activity and the nature of happiness. But a difference must be pointed out. The $\varepsilon^{\prime} \delta \circ \xi \alpha$ about what happiness consists in (i.e. that it is pleasure, honor or wealth) are not correct in and of themselves; they must be subjected to a dialectical analysis after which they turn out to be

${ }^{10}$ Cf. Topics, I, Chapters 1 and 2 and 10 through 14. 
partly correct and partly incorrect. The item of knowledge concerning actions and states of character cannot be like this; Aristotle nowhere qualifies it or analyzes it any further. Rather it must be something which is known and which is correct as it stands. Thus it must have the status of a self-evident item of common sense for most men and in Aristotle's moral psychology it must have the status of a self-evident first principle. (Philosophically, a more broadly based defence of the item of knowledge could be made using Aristotle's doctrines of potentiality and actuality.)

Question 2) concerns the distribution of the item of knowledge

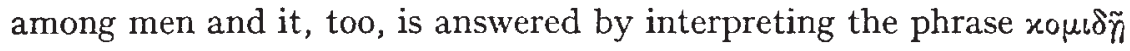

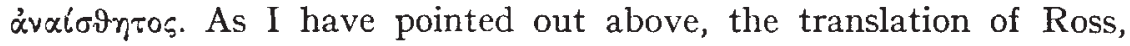
"thoroughly senseless," well fits the context. If this is correct and if, as I tried to show in answering question 1), the item of knowledge must be known by most men as a dictum of common sense, then the majority of men must have this knowledge and it is likely that Aristotle might even make the strong claim that most men know this. To put the matter the other way around, the men who are ignorant of this are beyond the bounds of sense and are probably so deficient that they cannot be counted as moral agents. Since Aristotle clearly wants to count most men as moral agents, then most men must know and be able to use this item of knowledge. ${ }^{11}$

Questions 3), 4) and 5) can be answered together. If men do know that actions of certain kinds lead to corresponding states of character, then that knowledge makes them responsible for the states of character which they have acquired. But this is possible only if it is possible to act contrary to an established character. ${ }^{12}$ One could imagine a case in which a man knew that the actions he performs will lead to a corresponding state of character but nevertheless he is unable to act contrary to his existing state of character. The quote from the (iategories (13 a $23-13$ a 31 ) which I have given above makes it clear that Aristotle believes that actions contrary to states of character are

\footnotetext{
11 However, this should not be taken as implying that a majority or even a large part of the population possesses this item of knowledge. Aristotle's views concerning the moral deficiency of slaves, women, the young, and barbarians are well known. Rather "men" as I am using the term in interpreting Aristotle must be restricted to educated, mature, male Athenian citizens.

${ }^{12}$ It is also possible if one can establish a particular state of character not over against its contrary, but rather from having no state of character of the relevant kind at all.
} 
indeed possible. ${ }^{13}$ Thus Aristotle must believe that there are cases in which a man could change an established state of character. Since this kind of action is possible and since men must know that this kind of action is possible, it follows that men can be held responsible for the states of character which they have. Thus the notions of responsibility for states of character, the possibility of acting contrary to an established state of character and acquiring contrary states of character are intimately related to one another in the sense that if one of these is possible then they all are. And all three of these are possible only on the grounds that men actually know and use the item of knowledge that certain kinds of actions lead to the establishment of certain kinds of states of character. If these considerations are correct then a man ignorant of the item of knowledge can not be held responsible for his states of character although he might be changed due to outside influences.

Left unanswered in this discussion, because there does not seem to be adequate evidence in the text, is the basic question as to whether every state of character is changeable or whether some states of character are entirely unchangeable. That some states of character are changeable is clear but there is no explicit statement in the text that all states of character are changeable nor does Aristotle give any criteria for distinguishing between changeable and non-changeable states of character. Also left unanswered are questions as to the relations between the item of knowledge and the problems of the weakness of the will, the practical syllogism and the nature of practical wisdom.

\section{University of Missouri}

\footnotetext{
13 Also, Ethics 1114 b $30 \mathrm{ff}$. seems to imply that acting contrary to a state of character is possible: "But actions and states of character are not voluntary in the same way; for we are masters of our actions from the beginning right to the end, if we know the particular facts..." (Ross trans.) This seems to mean that if a man has the state of character of being a coward, then he cannot now act as a brave man would act but he does not have to act entirely as a coward would act either.
} 